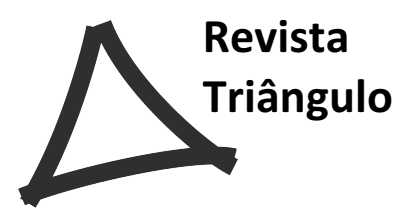

\title{
LICENCIANDOS EM FÍSICA E MATEMÁTICA: ASPECTOS NA CONSTITUIÇÃO DE UMA IDENTIDADE
}

\author{
TEACHER TRAINING IN PHYSICS AND MATHEMATICS: ASPECTS IN IDENTITY \\ CONSTITUTION
}

\author{
Júlio Henrique da Cunha Neto ${ }^{1}$ \\ Daniel Fernando Bovolenta Ovigli ${ }^{2}$
}

\begin{abstract}
RESUMO
O estágio curricular supervisionado, nos cursos de licenciatura, caracteriza-se como momento de especial importância no percurso formativo dos futuros professores e assume grande relevância frente às diretrizes curriculares. $\mathrm{O}$ presente trabalho visa à apresentação dos resultados parciais de um projeto de pesquisa que busca compreender a transformação do licenciando em professor a partir do estágio supervisionado, focalizando os cursos de Física e Matemática. Partimos do pressuposto de que o perfil acadêmico configura-se como contributo à identidade profissional do professor. Os resultados aqui apresentados centram-se na seguinte questão-diretriz: quem é o sujeito ingressante no curso de formação docente nessas áreas? Desenvolvido em uma Instituição de Ensino Superior, foi empregado questionários como instrumento de coleta de dados, em uma perspectiva de pesquisa exploratório-descritiva. Cabe destacar a importância dos hábitos culturais na formação dos estudantes, pouco presente segundo os dados da pesquisa. Assim, o conjunto de novos dados e análises permitirão avanços em relação à reflexão acerca da constituição identitária dos licenciandos em Física e Matemática.
\end{abstract}

Palavras-chave: Licenciatura em matemática. Licenciatura em Física. Estágio Curricular Supervisionado. identidade profissional.

\begin{abstract}
The supervised internship in Physics and Mathematics undergraduate courses is characterized as a moment of particularly importance when we consider the teacher training, especially for National Curriculum Guidelines from Brazilian Ministry of Education. This article aims to present the partial results of a research project that aims to understand the teacher training from supervised internship, focusing Physics and Mathematics undergraduate courses. We assume that the academic profile is configured as a contribution to teacher professional identity. The results presented focus on the question-guideline: who is the person that studies in these undergraduate courses? Developed in a public institution of higher education, we employed questionnaires, in an exploratory and descriptive research perspective. The study highlights the importance of cultural habits in students training, little present, according to research data. Thus, the set of new data and new analysis will enable the advancement of discussion about identity constitution of undergraduates in Physics and Mathematics.
\end{abstract}

Keywords: Mathematics undergraduate course. Physics undergraduate course. Supervised Internship. Teachers' Professional Identity.

\footnotetext{
${ }^{1}$ Universidade Federal do Triângulo Mineiro - UFTM. E-mail: julio_h_neto@ hotmail.com.

${ }^{2}$ Universidade Federal do Triângulo Mineiro - UFTM. E-mail: danielovigli@gmail.com.

Projeto financiado pela Fapemig - Processo APQ-03414-12
} 


\section{Introdução}

A formação de professores é um desafio presente no âmbito educacional, discutida em congressos, grupos de pesquisa, seminários, entre outros ambientes acadêmicos. As práticas formativas construídas no Estágio Curricular Supervisionado e a identidade profissional compõem essas discussões, apresentando elementos presentes na trajetória e na constituição de um sujeito, enquanto docente.

No entanto, o sujeito, antes de licenciando, antes de professor, constitui-se ser. Ser humano. Uma construção contínua, perene enquanto há vida. Nesse fazer-se, busca profissionalizar-se, inserir-se como ser atuante na sociedade em que vive. Ao optar por ser licenciando, portanto futuro professor, depara-se com questões próprias do ser e outras mais, inerentes à condição docente: o que precisa saber? Quais conhecimentos deve mobilizar? Quais ações executar? Como agir? Onde focar? Conhecimentos específicos ou conhecimentos pedagógicos? Teoria ou prática? A esse respeito, Miguel Arroyo (2000, p.33) afirma:

O ofício de mestre faz parte de um imaginário onde se cruzam traços sociais afetivos, religiosos, culturais, ainda que secularizados. A identidade de trabalhadores e de profissionais não consegue apagar esses traços de uma imagem social, construída historicamente. Onde todos esses fios se entrecruzam. Tudo isso sou. Resultei de tudo.

Compreender esse processo de transformação da posição de aluno para a de professor, em especial para a área de exatas, em Física e Matemática, supõe olhar para o trabalho realizado no âmbito de cursos de licenciatura nessas duas áreas, bem como para a trajetória pessoal de cada licenciando. Para tal, justifica-se a escolha de trabalhar com um grupo de disciplinas que possibilitam o contato direto com a Educação Básica, e com as várias faces e interfaces da profisssão docente: o Estágio Curricular Supervisionado (ECS). Não se menospreza, todavia, a contribuição das demais disciplinas para a formação do licenciando, pois acreditamos que todos os conhecimentos serão mobilizados na prática docente.

Mas como analisar esse processo de constituição sem conhecer quem é esse sujeito? Quais elementos trazem ao longo de sua trajetória pessoal que contribuem para a formação de sua identidade como professor? Quais os desafios vivenciados em sua formação? Quais os impactos de suas ações no ECS para a Educação Básica? Conhecer esse processo de constituição pressupõe considerar o sujeito diretamente nele envolvido, o contexto de sua 
formação e o impacto de suas ações. A esse respeito, Colombo-Junior (2009, p. 28) afirma que “(...) olhando a formação inicial dos futuros professores, e em especial os estágios supervisionados, deparamos com inúmeras possibilidades de fazer um ensino melhor do que outrora".

Essa proposta refere-se à primeira etapa de um projeto, desenvolvido pelo Grupo de Estudos e Pesquisa em Educação e Cultura (GEPEDUC), intitulado "Investigando a transformação do licenciando em professor a partir do Estágio Curricular Supervisionado", e propõe investigar a consolidação do licenciando enquanto docente a partir dos estágios , bem como a trajetória e as experiências dos acadêmicos dos cursos de Licenciatura em Matemática, Física, Química e Ciências Biológicas, todos ofertados no período noturno. A questão que orienta esse projeto é: "Como o professor em formação inicial se consolida enquanto professor e quais os impactos de suas ações na Educação Básica?”. Neste texto, focalizaremos resultados preliminares relativos à investigação desenvolvida junto aos cursos de Licenciatura em Física e Matemática, ofertados por uma instituição federal de educação superior.

\section{Estágio Curricular Supervisionado: um Espaço de Formação}

Diversas pesquisas são realizadas sobre a importância do período de Estágio Curricular Supervisionado nos cursos de licenciatura. Gatti e Barreto (2009) destacam sobre a importância desse período, mas fazem um alerta de que os projetos pedagógicos e as ementas dos cursos não estão fornecendo informações sobre como esse período é realizado, como é supervisionado e acompanhado.

Para Gatti, Barreto e André (2011) há uma fragilidade referente à imprecisão dos dados referentes ao período de estágio e isso inviabiliza uma apreciação dos acontecimentos nos espaços de formação, ou seja, no campo de estágio. As autoras ainda alertam que os estagiários muitas vezes estão envolvidos em atividades apenas de observação e não em práticas efetivas para a sua formação.

A esse respeito, destaque-se que o Estágio Curricular Supervisionado é regulamentado pela Lei n. 11.788 de 25 de setembro de 2008 que dispõe sobre o estágio de estudantes, em consonância com a Lei n. 9.394/96 que estabelece as Diretrizes e Bases da Educação Nacional (LDBEN). Segundo a lei 
Estágio é ato educativo escolar supervisionado, desenvolvido no ambiente de trabalho, que visa à preparação para o trabalho produtivo de educandos que estejam frequentando o ensino regular em instituições de educação superior, de educação profissional, de ensino médio, da educação especial e dos anos finais do ensino fundamental, na modalidade profissional da educação de jovens e adultos. (BRASIL, 2008, p.1).

O período de estágio pode auxiliar o sujeito a identificar novas e diversas estratégias de soluções de problemas encontrados na prática. Trata-se de um momento de formação para a futura profissão, mas não se constitui vínculo empregatício. Conhecer o espaço de atuação, as atividades desenvolvidas, o trabalho realizado pelos docentes nas escolas são atividades que o licenciando irá realizar. Ele poderá contribuir levando novidades para a escola campo num movimento de colaboração/cooperação. É um momento de crescimento pessoal e profissional, "é um processo criador de investigação, explicação, interpretação e intervenção na realidade" (PIMENTA, 1997, p.73-74).

Os estágios assumem, portanto, o papel de componente integrador, articulando os didático-pedagógicos com os de conteúdo específico. Teria, portanto, missão essencial na formação de professores, uma vez que possibilita a ligação entre a teoria e a prática (ZIMMERMANN e BERTANI, 2003). Essa centralidade é, inclusive, reiterada com as diretrizes curriculares nacionais de formação de professores, que elevaram para 400 o número de horas destinadas ao estágio supervisionado (BRASIL, 2001).

\section{Identidade: aspectos que constituem o profissional docente}

A identidade, para Dubar (2005), é o resultado do processo de socialização entre os sujeitos, é um período que compreende o encontro dos processos relacionais e biográficos. $\mathrm{O}$ primeiro diz respeito à análise dos sujeitos pelo outro e o segundo corresponde à identidade para si. Para o autor, ambas, a identidade para si e para o outro, não estão separadas, visto que "a identidade para si é correlata ao outro e ao se reconhecimento: nunca sei quem sou a não ser pelo o olhar do outro." (DUBAR, 2005, p.135).

Nesse sentido o autor afirma que a "(...) identidade nunca é dada, é sempre construída e a (re) construir, em uma incerteza maior ou menor e mais ou menos durável" (DUBAR, 2005, p. 104), é produto de sucessivas socializações, de trocas. Socialização, destacada pelo autor, como um procedimento pelo qual o sujeito pode ir desenvolvendo seu 
modo de agir, interagir e estar no mundo; como um processo dinâmico que vai se transformando, está sempre em construção e reconstrução ao longo da vida (DUBAR, 2005).

Para tanto, o processo de constituição da identidade, segundo Dubar (2005), é compreendido como formações identitárias, pois os sujeitos assumem várias identidades ao longo da vida. $\mathrm{O}$ autor destaca algumas categorias que podem auxiliar nessa identificação, tais como as características éticas, regionais, profissionais, as quais o outro usa para nos identificar. Define essas categorias com atos de atribuição e atos de pertença (grifos nossos). Os atos de atribuição dizem respeito a identidade para o outro é definida pelo "tipo de homem (ou de mulher) que você é", Os atos de pertença referem-se do "tipo de homem (ou mulher) você quer ser" (DUBAR, 2005, p. 106). Sendo assim, compreendemos que o ato de atribuição corresponde à identidade para o outro e o ato de pertença, a identidade para si.

Cada professor, portanto, tem sua própria trajetória de saber formalizado, construído também a partir de seu contato com os mais diversos estabelecimentos especializados. No caso da presente investigação, os licenciandos dos cursos de Física e Matemática apresentam em comum um saber específico em seu currículo de formação. Segundo Dubar (2005, p.151) “(...) a unidade elementar de definição é a especialidade, isto é, a competência especializada adquirida pela formação de base" (grifo nosso). A licenciatura é a habilitação profissional comum a todos os professores, critério legal para pleitear o cargo. Pode-se marcar a atuação desse profissional também no saber-fazer, nas experiências fruto das aprendizagens cumulativas. $\mathrm{O}$ cargo é “(...) a competência especializada adquirida pela formação de base somada ao saber-fazer adquiridos”. A carreira [docente] sanciona o domínio progressivo da junção dos conhecimentos (saberes formalizados) e dos saberes-fazeres (DUBAR, 2005, p. 151).

A construção identitária também se dá por meio da interiorização da identidade atribuída pelos outros para si. Esta identidade atribuída deve fazer sentido para o sujeito, pois irá entrar em contato com sua trajetória, com suas histórias, com a maneira de como se percebe e como percebe a realidade objetiva (DUBAR, 2005). As categorias de identidade empregadas pelas instituições e pelos seus agentes são necessariamente modelos ou categorias de identidades socialmente reconhecidas pelos outros, inclusive pelo sujeito em questão: estas, no entanto, variam de acordo com os espaços sociais nos quais ocorrem as interações.

A construção da identidade, portanto, passa pela articulação entre o subjetivo e objetivo, entre identidade herdada e visada e também “(...) depende dos modos de reconhecimento das instituições legítimas e pelos seus agentes que estão diretamente em 
relação com os sujeitos em causa" (DUBAR, 2005, p. 108). O autor pondera que a negociação identitária se dá pelos processos de comunicação: “O desafio é certamente articular essas duas dimensões complexas, mas autônomas: não se faz a identidade das pessoas sem elas e, contudo, não se pode dispensar os outros para forjar a sua própria identidade” (p. 110).

\section{Metodologia}

Com o objetivo de investigar o perfil acadêmico dos licenciandos dos cursos de Física e Matemática de uma universidade federal situada no estado de Minas Gerais, realizamos o estudo exploratório-descritivo aqui relatado. Neste momento, a questão de pesquisa proposta foi: "quem é o sujeito ingressante nos cursos de formação docente em Física e Matemática?". Buscamos, pois, investigar o impacto desse perfil na constituição da identidade do professor de Física e de Matemática formado pela instituição.

Cabe destacar que toda pesquisa assume um componente subjetivo, assim como qualquer investigação deve ser lida sob diferentes óticas. Visando à caracterização dos elementos comumente presentes em pesquisas de natureza qualitativa, Bogdan e Biklen (1994) apontam o fato de que uma pesquisa pode ser mais ou menos qualitativa dependendo dos instrumentos que utiliza.

Considerando tais pressupostos, optamos pelo questionário como instrumento de coleta de dados, elaborado a partir de questões construídas coletivamente pelo grupo de pesquisa ao qual o projeto se vincula. As seguintes dimensões compuseram o questionário: (i) características pessoais, (ii) formação durante a Educação Básica, (iii) atuação profissional, (iv) condições socioeconômicas e (v) apoio recebido e condições necessárias para cursar a graduação.

Cabe ressaltar que questões ou questionários refletem os interesses daqueles que o constroem e, dessa forma, incumbe aos investigadores tentar reconhecer e tomar em consideração os seus enviesamentos, como forma de lidar com eles. Para Bogdan e Biklen (1994), quanto mais controlada e intrusiva for a investigação, maior a probabilidade de se verificarem "efeitos do observador" no comportamento dos investigados. Quando os investigadores qualitativos estão interessados no modo como as pessoas normalmente se comportam e pensam nos seus ambientes naturais, tentam agir de modo a que as atividades que ocorrem na sua presença não difiram significativamente daquilo que se passa na sua ausência: tais pressupostos foram considerados quando da aplicação dos questionários. 
Em um segundo momento, a análise textual discursiva orientou o olhar sobre o material empírico. Tal abordagem fundamenta-se nos significados que o pesquisador atribui aos dados, pautado na literatura. Portanto o pesquisador, em seu trabalho, é autor das interpretações que constrói a partir dos textos que analisa. Moraes (2003, p. 192) afirma que: "Se um texto pode ser considerado objetivo em seus significantes, não o é nunca em seus significados".

\section{Resultados e Discussão}

Vinte e três estudantes responderam ao questionário. Apenas cinco estudantes apresentam mais de 30 anos e, pelo menos em alguma etapa de sua formação ao longo da Educação Básica, estudaram em instituição pública. A Tabela 1 indica a naturalidade dos licenciandos.

Tabela 1: naturalidade

\begin{tabular}{|c|c|c|c|}
\hline Licenciatura & Física & Matemática & Total \\
\hline Naturalidade & Frequência & Frequência & \\
\hline $\begin{array}{c}\text { Belo } \\
\text { Horizonte/MG }\end{array}$ & 1 & - & 1 \\
\hline $\begin{array}{c}\text { Conceição das } \\
\text { Alagoas/MG }\end{array}$ & 1 & - & 1 \\
\hline Franca/SP & 1 & - & 1 \\
\hline Ituverava/SP & - & 1 & 1 \\
\hline Osasco/SP & 1 & - & 1 \\
\hline Patrocínio/MG & - & 1 & 1 \\
\hline $\begin{array}{l}\text { Ribeirão } \\
\text { Preto/SP }\end{array}$ & - & 1 & 1 \\
\hline $\begin{array}{c}\text { Rio de } \\
\text { Janeiro/RJ }\end{array}$ & - & 1 & 1 \\
\hline Uberaba/MG & 4 & 11 & 15 \\
\hline Total & 8 & 15 & 23 \\
\hline
\end{tabular}

Reiterando que a identidade é permanentemente construída, o fato de cursar graduação em instituição externa, muitas vezes, a seus municípios de origem, configura-se como processo social que coloca o indivíduo em interação com novos setores do mundo objetivo da sociedade, deslocando-o do núcleo familiar. Neste processo de socialização secundária, na universidade, os conjuntos institucionais e construção de saberes profissionais, passam a ser percebidos e vividos (BERGER e LUCKMANN, 2003). Ademais, chama a atenção três sujeitos do curso de Licenciatura em Física terem feito cursos técnicos em 
edificações, mecânica e radiologia áreas que, de acordo com o Catálogo Nacional de Cursos Técnicos contam com conteúdos de física, denotando alguma familiaridade com a área. Outros três, sendo esses licenciandos em Matemática, também realizaram cursos profissionalizantes, nas áreas de eletroeletrônica, agrícola e enfermagem, o que não demonstra uma mesma familiaridade, como apresentada pelos estudantes de física. Dos três licenciando em Física que afirmam trabalhar, um atua na área administrativa e dois já estão inseridos na área educacional, em conjuntos institucionais que congregam a construção de saberes profissionais para estes sujeitos. Dentre os estudantes de Matemática, nove relataram que trabalham, dentre eles, três na docência. Carvalho $(1984$, p. 55) destaca que grande parte dos estudantes frequenta o curso noturno para combinar trabalho e estudo, realidade dos estagiários dessa pesquisa. "O período noturno é reservado ao aluno que trabalha, sendo essa a maior diferenciação entre os períodos".

Quanto aos hábitos de consumo cultural (relativos à frequência em cinema, leitura $\mathrm{e}$ televisão), os dados seguem sistematizados na Tabela 2:

Tabela 2: hábitos de consumo cultural (F: Física e M: Matemática)

\begin{tabular}{|c|c|c|c|c|c|c|c|c|c|c|c|c|}
\hline \multirow{2}{*}{$\begin{array}{c}\text { Frequência/ } \\
\text { Atividades }\end{array}$} & \multicolumn{2}{|c|}{ Assistir Televisão } & \multicolumn{2}{|c|}{ Atividade Artística } & \multicolumn{2}{|c|}{ Baladas } & \multicolumn{2}{|c|}{ Cinema } & \multicolumn{2}{|c|}{ Esporte } & \multicolumn{2}{|c|}{ Namorar } \\
\hline & $\mathbf{F}$ & M & $\mathbf{F}$ & M & $\mathbf{F}$ & $\mathbf{M}$ & $\mathbf{F}$ & M & $\mathbf{F}$ & M & $\mathbf{F}$ & M \\
\hline Nunca & - & - & - & 1 & - & - & - & - & - & 1 & - & - \\
\hline Raramente & 1 & 2 & 1 & - & - & 1 & - & 4 & - & - & - & - \\
\hline Às vezes & - & 1 & - & - & 1 & 1 & 1 & 2 & 1 & 1 & - & - \\
\hline Usualmente & 1 & 3 & - & 3 & 1 & 1 & 3 & 1 & 1 & - & 3 & 5 \\
\hline Sempre & 1 & 1 & - & - & 1 & - & & - & - & 1 & & 2 \\
\hline $\begin{array}{l}\text { Não } \\
\text { responderam }\end{array}$ & 7 & 8 & 9 & 11 & 7 & 12 & 6 & 8 & 8 & 12 & 7 & 8 \\
\hline Total & 10 & 15 & 10 & 15 & 10 & 15 & 10 & 15 & 10 & 15 & 10 & 15 \\
\hline
\end{tabular}

Fonte: produzido pelos autores

Dubar (2005), ao investigar a vivência dos indivíduos, aponta a relação que ações como as que são acima descritas têm com a construção da identidade. Cinema, leitura e televisão, por exemplo, entram em relação com a dimensão da subjetividade, ou seja, com a representação que o sujeito tem de si próprio (processo biográfico) e com a identidade que se tem para o outro (processo relacional). Tais processos se coadunam à socialização primária, gestada no núcleo familiar. 
Tabela 3: ocupação do pai e da mãe

\begin{tabular}{|c|c|c|c|c|c|}
\hline \multicolumn{3}{|c|}{ PAI } & \multicolumn{3}{|c|}{$\mathbf{M A ̃ E} \mathbf{E}$} \\
\hline Ocupação & Física & Matemática & Ocupação & Física & Matemática \\
\hline Bibliotecário UFOP & 1 & - & Aposentada & 1 & 4 \\
\hline Chefe geral de manutenção & 1 & - & Doméstica & 2 & 4 \\
\hline Construtor civil & 1 & - & Dona de casa & 2 & \\
\hline Empresário & 1 & 3 & Empresária & 1 & 1 \\
\hline Engenheiro & 2 & - & Professora & 3 & - \\
\hline Falecido & 1 & 1 & Servente & 1 & - \\
\hline Gerente & 1 & - & Costureira & - & 1 \\
\hline Operário & 1 & - & Cuidadora de idosos & - & 1 \\
\hline Funcionário Público & - & 1 & Falecida & - & 1 \\
\hline Aposentado & - & 3 & Funcionária Pública & - & 2 \\
\hline Pedreiro & - & 1 & & & \\
\hline Motorista & - & - & & & \\
\hline Professor & 1 & - & & & \\
\hline
\end{tabular}

Fonte: produzido pelos autores

Destaque-se que cada docente apresenta sua trajetória própria de saber formalizado, construído nos mais diversos estabelecimentos pelos quais passou. Ao mencionar que a carreira docente não é transmitida para a geração seguinte, Pio (2012) assinala que fatores advindos dos diversos sujeitos e gerações, com suas formações de base, saberes-fazeres e experiências, somados às particularidades de cada instituição profissional, vão caracterizando diferentes grupos de profissionais.

Quando Berger e Luckmann (2003) analisam as etapas de socialização às quais os sujeitos estão expostos no decorrer de suas trajetórias, eles a definem como “(...) introdução do indivíduo no mundo objetivo de uma sociedade ou de um setor dela” (p. 175). Quanto a uma possível interferência das mães nessa opção, cabe destacar que a socialização considera a identificação pelo outro e a auto-identificação (a identidade objetivamente atribuída e a identidade subjetivamente apropriada).

Destaque-se que a identidade pode ser mantida ou mesmo reconfigurada a partir das interações sociais. Nesse processo de socialização secundária, ocorrida no contexto universitário, emerge a participação dos estudantes em programas de ensino, pesquisa e 
extensão ofertados pela IES. A esse respeito, em relação aos discentes do Curso de Física, os seguintes números foram levantados: PIBID (7), monitoria (1) e participação em PET, extensão e bolsa permanência não foram apontados por nenhum respondente; iniciação científica é desenvolvida por cinco respondentes, o que também denota a aproximação dessa área com a pesquisa. Um deles afirmou ter atuado no ensino fundamental, em um movimento de aproximação com a identidade do professor. Louro (2000) afirma que não pretende imputar ao espaço escolar a responsabilidade de explicar as identidades sociais ou impô-las de forma permanente. A autora reconhece que tais experiências apresentam sentido e constituem parte expressiva de muitas histórias pessoais e profissionais.

No que tange à participação em projeto/programa na Universidade dos estudantes de Matemática, 13 alunos são bolsistas, sendo PET (6), PIBID (6), Monitoria (1) e dois não recebem bolsa. Destaca-se que a quantidade de estudantes que participa de algum programa, pois esses são espaços de trocas de experiências, de interações sociais, nas quais as identidades vão sendo construídas e reconstruídas, é um espaço de socialização secundária (na universidade), no qual os saberes específicos e profissionais vão sendo percebidos e vividos (DUBAR, 2005).

Tabela 4: renda familiar e do estudante

\begin{tabular}{|c|c|c|c|c|c|}
\hline Renda familiar & Física & Matemática & Renda do estudante & Física & Matemática \\
\hline Até R\$ 724,00 & 2 & & Até R\$ 724,00 & 1 & 2 \\
\hline De R\$ 725 a R\$ 1.448,00 & & 3 & De R\$ 725 a $R \$ 1.448,00$ & & 3 \\
\hline $\begin{array}{l}\text { De R\$ 1.449,00 a R\$ } \\
2.172,00\end{array}$ & 3 & 2 & De R $\$ 1.449,00$ a R $\$ 2.172,00$ & 1 & 2 \\
\hline $\begin{array}{l}\text { De R\$ 2.173,00 a R\$ } \\
2.896,00\end{array}$ & & 4 & De $\mathrm{R} \$ 2.173,00$ a $\mathrm{R} \$ 2896,00$ & 1 & 1 \\
\hline $\begin{array}{l}\text { De R\$ 2.897,00 a R\$ } \\
\text { 3.620,00 }\end{array}$ & & 3 & De $\mathrm{R} \$ 2.897,00$ a $\mathrm{R} \$ 3.620,00$ & & 1 \\
\hline $\begin{array}{l}\text { De R\$ 3.621,00 a R\$ } \\
4.344,00\end{array}$ & & 1 & Não responderam & 7 & 6 \\
\hline $\begin{array}{l}\text { De R\$ 5.069,00 a R\$ } \\
5.793,00\end{array}$ & & 1 & & & \\
\hline R\$ 5.793,00 a R\$ 6.516,00 & 1 & & & & \\
\hline $\begin{array}{llll}R \$ & 7.240,00 & \text { a } & \text { R\$ } \\
14.479,00 & & & \\
\end{array}$ & 2 & & & & \\
\hline Não responderam & 2 & & & & \\
\hline
\end{tabular}

Fonte: produzido pelos autores

A realidade na qual o sujeito vive e convive é de fundamental importância na constituição de sua identidade, ou seja, a formação de base que teve ao longo de sua trajetória de vida. Destaca-se que a renda familiar e também individual dos estudantes da licenciatura ainda é baixa, conforme apontam muitas pesquisas. 
Partindo do princípio de que a articulação entre o subjetivo e o objetivo são fundamentais na constituição da identidade dos sujeitos (DUBAR, 2005) o fato de o sujeito trabalhar ou ter que trabalhar para o seu sustento e de sua família são escolhas realizadas diante da situação, no momento, vivida por eles e que vão se configurando em diferentes categorias ou modelos identitários. Nesse contexto, a renda é fundamental no sentido de possibilitar aos sujeitos maiores investimentos em diversos setores que contribuem para sua constituição identitária.

\section{Considerações}

O texto procurou refletir sobre a constituição da identidade do licenciandos em física e matemática considerando seus perfis acadêmicos, constituídos a partir de um questionário. Devido à carência de referências que analisem a identidade desse profissional formado na rede federal de educação, julgou-se relevante pensar e discutir sobre sua constituição, uma vez que sua atuação está atrelada ao ensino, pesquisa e extensão, tripé este que é o alicerce das instituições de ensino superior.

Em relação à socialização secundária dos estudantes, chama a atenção o fato de grande parte ser oriundos de outras cidades; a busca por novos conhecimentos em outros espaços com a inserção em programas como o PIBID, ou seja, a sua introdução em um mundo desconhecido, no qual será identificado pelo outro e também se auto-identificará. Esse processo de socialização lhe permitirá configurar e reconfigurar seus modelos identitários.

Também cabe destacar a importância dos hábitos culturais na formação dos estudantes, pouco presentes segundo os dados da pesquisa. Apesar de a maioria dos estudantes terem pelo menos um dos pais com formação superior, esse hábito cultural não é tão difundido em seu cotidiano. Assim, o conjunto de novos dados e análises permitirão avançar em relação à reflexão acerca da constituição identitária dos licenciandos em Física e Matemática.

\section{Referências}

ARROYO, Miguel G. Oficio de mestre: imagens e auto-imagens. Petrópolis: Vozes, 2000.

BERGER, Peter; LUCKMANN, Thomas. A construção social da realidade: tratado de sociologia do conhecimento. Petrópolis, RJ: Vozes, 2003 
BOGDAN, R; BIKLEN, S. Investigação Qualitativa em Educação: uma introdução à teoria e aos métodos. Porto Editora: Lisboa, 1994.

BRASIL. Ministério da Educação. Lei $n^{\circ} .11 .788$, de 25 de agosto de 2008. Dispõe sobre o estágio de estudantes. Disponível em: <http://www.planalto.gov.br/ccivil_03/_Ato20072010/2008/Lei/L11788.htm>. Acesso em: 23 abr. 2013.

BRASIL. Diretrizes Curriculares Nacionais para formação de professores de educação básica, em nível superior, curso de licenciatura, de graduação plena. CP Parecer 009/2001, de 8 de CP Parecer 009/2001 maio de 2001a. Documenta n. 476, p. 513-562.

CARVALHO, C. P. Ensino noturno: realidade e ilusão. São Paulo, Cortez Autores Associados, $1984.112 \mathrm{p}$

COLOMBO-JUNIOR, P.D. Enfim Professor. E agora? ALEXANDRIA Revista de Educação em Ciência e Tecnologia, v.2, n.1, p.27-44, mar. 2009.

DUBAR, C. A socialização: construção das identidades sociais e profisisonais. São Paulo: Martins Fontes. 2005.

GATTI, B.A.; BARRETO, E.S.S. Professores: aspectos de sua profissionalização, formação e valorização social. Brasília, DF: UNESCO, 2009.

GATTI, B. A. BARRETO, E. S., ANDRÉ, M. E. D. A. Políticas docentes no Brasil: um estado da arte. Brasília: UNESCO, 2011.300 p.

LOURO, G. L. (Org.). O corpo educado: pedagogias da sexualidade. Belo Horizonte, MG: Autêntica, 2000.

MORAES, R. Uma tempestade de luz: a compreensão possibilitada pela análise textual discursiva. Ciência \& Educação, Bauru, v. 9, n. 2, p. 191 - 211, 2003.

PIMENTA, S. G. Formação de Professores: saberes da docência e identidade do professor. Nuances, vol III, Presidente Prudente, 1997.

PIO, A. Técnicos em assuntos educacionais do Colégio Pedro II: história, identidade e limites de atuação. 2012. 166 f. Dissertação (Mestrado) - Universidade Federal do Rio de Janeiro, Rio de Janeiro, 2012.

ZIMMERMANN, E.; BERTANI, J.A. Um novo olhar sobre os cursos de formação de professores. Cad.Bras.Ens.Fís., v.20, n.1: 43-62, 2003.

RECEBIDO EM: 03/03/2016

APROVADO PARA PUBLICAÇÃO EM: 29/06/2016 